\title{
Psychometric Properties of Cognitive Emotion Regulation Questionnaire (CERQ) and Its Relationship with Depression, Anxiety and Stress among Students in Tehran
}

\author{
Maryam Mirzaee \\ mona_mirzaei2001@yahoo.com
}

\author{
Doi:10.5901/mjss.2016.v7n2s2p54
}

\begin{abstract}
The individuals use various coping strategies to cope with stress. Selection of suitable coping strategies against mental pressures can reduce effect of pressures on mental health, resulting in the person's more adjustment. With regard to what mentioned above, the present research has been conducted aiming at identifying psychometric properties including validity and normalization of The Defense Style Questionnaire (DSQ) among students, so that overview of these properties requires performing factor analysis. A sample group with sample size (485) has been selected among the statistical population based on the common methods in factor analysis research using cluster sampling. 85 individuals have been discarded among them due to lack of collaboration and as the result a sample group with sample size (400) among students in Tehran city have been undergone study. The Defense Style Questionnaire (DSQ) as the instrument used in the present research measures defensive behavior in daily life. According to the results from this research, there is a significant relationship between psychometric properties of Cognitive Emotion Regulation Questionnaire (CERQ) and its relationship with depression, anxiety and stress among students in Tehran.
\end{abstract}

Keywords: Psychometry, Cognitive Emotion Regulation Questionnaire (CERQ), depression, anxiety, stress

\section{Introduction}

A group of experts has called stress as the common disease of century. This age might be perhaps the age of stress and mental pressures, at which the man has exposed to stressful factors more than any other time and enclosed with numerous problems from any side; in a world filled with commotion, how can avoid mental pressures or cope with them? How can detect mental pressure and its complications? How can cope with stress before reaching to acute stages and suppress it. Distress might be result of cognitive or physical processes, but representation of distress is in an emotional state specified with tendency to the practice to reduce or release emotional experience. Distress tolerance has been specified with the ability to experience and resist against negative psychological states (Simon \& Gaher, 2005). Firstly, the individuals with low distress tolerance know emotion intolerable and fail to handle their distress. Secondly, these individuals do not accept emotion and feel embarrassed of this emotion, because they underestimate the ability to cope with emotions. The third major property of emotional regulation in the individuals with low distress tolerance is the attempt by these individuals to avoid negative emotions and relieve negative experienced emotions. It should be noted that if these individuals fail to relieve these emotions, all their attention to this emotion will be distressed and their performance will reduce (Simons and Gahr, 2005). Regardless of this point that to which extent we can cope with problems, situations will raise in life which we inevitably feel mental pressure. Our motives are not always satisfied easily that obstacles must be discarded, showing patience to lateness. Under encounter with the barriers to people's prosperity, a specific response method grows in each of them. The response method to frustrating situations to a large extent indicates that the man's adjustment with life is sufficed or not. The individuals should feel mental pressure so as to engage in an activity naturally. Mild emotional arousal keeps the person alert during his work process; while the people's life comes with Silence and calmness, they feel ill and seek exciting things.

\section{Theoretical Background and Literature Review}

There are convincing evidences that if we believe a behavior can reduce negative feelings and emotions, we more likely to get into that behavior even if the behavior are unhealthy (Fisher and Smith, 2008). Further, there are convincing evidences that show some unhealthy behaviors can reduce negative emotions rapidly and this is unfortunate because one learns that such behavior can rapidly reduce negative affect (Smith et al Andrlych, 2007). In the psychoanalysis 
system, any mental disorder is associated with certain maladaptive defense mechanisms(Belaya, Dornelles, Belaya, 2006); defense mechanisms "I" that Freud has defined them unconscious approaches "I" to control instincts and impulses have been regarded as the most important concepts associated with unconsciousness that were introduced in psychoanalysis system to elaborate defensive function of mental system against anxiety and distress(Offer, Lavie, Gothelt, D and Apter, 2000). Belaya et al. displayed that defenses play a major role in person's mental health, e.g. projection has been reported as the substantial defense to depression (Belaya et al. 2006). a variety of investigations have supported this assumption, specified that there is a significant relationship between physical and mental health of individuals and their defense mechanisms(Band \& Perry, 2004). In this regards, the studies have also confirmed the significance of the relationship between therapeutic interventions and defense mechanisms, e.g. studies have shown that psychodynamic therapies that directly deal with patient's defenses help for reducing maladaptive defenses and increasing adaptive defenses(Cramer, 2000; Band \& Perry, 2004). Hence, it seems that there is a significant relationship between recovery and non-pathological defenses regardless of type of treatment. With regard to psychoanalysis approach, stressed people use certain defense styles that are classified to the groups of immature, neurotic and narcissistic. Each of these styles includes specific mechanisms (Kramer, 2000). Vaillant \& his colleague perceived that mental health associates to the developed defense mechanisms such as sublimation, suppression, humor and prediction. Those who use developed mechanism cope with mental pressure properly and give response to the conflict (Mohammad Pour yazdi, Birashk, Fata \& Dojkam, 2009).

Distress tolerance has been defined as the ability to insist on the purposeful activity in experiencing emotional distress (Leyro et al. 2009). Women than men tend to lower levels of distress tolerance, yet low distress tolerance is destructive without considering gender(Simons and Gahr, 2005). There are various ways that our emotions can raise problems. To some of us, emotion instability or rapid emotional changes, and release from various frustrating states are problematic. To some others, recurrent negative moods encountered with them more than others; to some others, Alexithymi (the inability to express feelings with words) which result in deep understanding of feeling are problematic. To others, lack of pleasure, lack of emotion, disconnection, numbness and inability to feel positive emotions in response to things that were previously enjoyable are problems. There are several other solutions that our emotions can become problematic to us, for which it cannot give a comprehensive list (Simons and Gahr, 2005). In the research by Azizi (2009), the correlation between distress tolerance and positive and negative emotions has obtained equal to 0.543 and 0.224 , respectively. In the research by Ward, Swan \& Jach (2001), there is a positive relationship between distress tolerance and mood acceptance. An emotion-focused coping strategy such as the use of alcohol and other factors may lead to the rapid escape of persons from the negative emotions (Lazarus, 1991). This strategy is considered as a suitable style especially for those who have low distress tolerance (Bernstein et al. 2010). In the research by Azizi, Mirzaei \& Shams (2010), it was specified that there is a positive significant correlation between all the subscales of difficulty in nonacceptance of emotional responses (Non-acceptance), difficulties engaging in goal-directed behavior (Goals), difficulties in impulse control (Impulse), lack of emotional awareness (Awareness), limited access to emotion regulation strategies (Strategies) and lack of emotional clarity (Clarity) (Azizi et al. 2010). Firstly, the individuals with low distress tolerance know emotion intolerable and fail to handle their distress, secondly these individuals do not accept emotion and feel embarrassed of it, because they underestimate their coping abilities (Simons and Gahr, 2005). Distress tolerance indicates the real ability of resistance against negative effect or aversion to mental or physical state (Brown, 2005; Leyro, 2010). Various conceptual models indicate that distress tolerance might play a central role in emergence or continuity of a variety of disorders. Studies have indicated that the individuals with antisocial personality disorder tend to express low levels of distress tolerance. Further, low level of distress tolerance is followed by more levels of tendency to suicide (Anestis, Bagge, and Tuli). According to the report by Chew (2006), the recent meta-analysis study indicates that effective strategies in Dialectic Behavior Therapy in treating depression symptoms include the strategies associated to acceptance, i.e. Core Mindfulness and Distress tolerance. Dialectic Behavior Therapy (DBT) refers to an approach that was invented at first with Borderline Personality Disorder, grounded on principles of acceptance and changes that proposes four intervention components in group therapy which include Fundamental universal awareness, distress tolerance as the components of acceptance, emotion regulation and interpersonal effectiveness as the components of change (Simons and Gahr, 2005). According to Miller's research, it was specified that DBT results in significant reduction in the positive symptoms of distress and increase of distress tolerance together with reduction of depression can indicate the relationship between depression and lack of distress tolerance. Distress tolerance has a negative relationship with scales of coping strategies including use of alcohol and marijuana and use of them for improvement (Azizi, 2009). Belaya et al.(2006) indicated that defenses play a major role in mental health, e.g. projection depression is featured defense(Belaya et al. 2006). With regard to what mentioned above, the major aim of research includes validity of the Defense Style Questionnaire (DSQ) and its relationship with coping strategies in the considered population. 


\section{Research Questions}

- $\quad$ whether the Defense Style Questionnaire (DSQ)has sufficient authenticity?

- $\quad$ whether the Defense Style Questionnaire (DSQ)has sufficient validity?

- $\quad$ what factors have saturated the Defense Style Questionnaire (DSQ)?

- $\quad$ whether a significant relationship exists between defensive mechanisms and coping strategies?

- $\quad$ whether a difference exists between defensive mechanisms among two genders?

\section{Research Method}

The present research is a descriptive exploratory study which has been conducted based on common principles and methods in psychometry. After collecting data, different stages of normalization including studying internal consistency of test, validity of test and factor analysis of major components and ultimately the correlation between two questionnaires are examined and analyzed.

\section{Statistical Population}

Since the present research aims to normalize Defense Style Questionnaire (DSQ), the sample size must be determined to a size representing the population in order that the research enjoys sufficient validity. Therefore, the sample group was selected with sample size (484) that all were among students in Tehran.

\section{Sample Group and Sampling Method}

Sample group was selected among the students in central Tehran branch using cluster method, which the questionnaires were distributed among 484 students and 84 questionnaires were omitted due to different reasons.

Measurement instruments

- Defense Style Questionnaire (DSQ)

- $\quad$ Coping Inventory for Stressful Situations (CISS)

\section{Data Analysis Method}

A-descriptive statistics: in this research, statistical indices(mean, variance and so forth) of tables have been displayed using descriptive statistics.

b-inferential statistics: the data were analyzed via existing statistical methods and the parameters of the population were estimated via statistical indices. Cronbach's alpha was used to determine validity and major components of questionnaire were analyzed to measure validity of questionnaire. To determine simple structure of questionnaire, principal components analysis using varimax rotation has been used; it should be noted that the statistical research methods were conducted using software SPSS.

\section{Research Findings}

\subsection{Descriptive statistics}

\subsubsection{Descriptive statistics}

\subsubsection{Descriptive statistics of research participants}

In this research, 400 boy and girl students in Tehran city were selected as the research sample group.

Table 1. Frequency distribution of age of participants

\begin{tabular}{|l|c|c|}
\hline Age & Frequency & Frequency percent \\
\hline Under 25 years old & 232 & $\% 58$ \\
\hline $25-35$ years old & 113 & $\% 28 / 2$ \\
\hline \multicolumn{3}{|c|}{} \\
\\
( 56
\end{tabular}




\begin{tabular}{|l|c|c|}
\hline Above 35 years old & 55 & $\% 13 / 8$ \\
\hline Sum & 400 & $\% 100$ \\
\hline
\end{tabular}

As observed in table 1, majority of the participants are at the age group under 25 years old and minority of participants are at the age group above 35 years old.

Table 2. Frequency distribution of gender of participants

\begin{tabular}{|l|c|c|}
\hline Gender & Frequency & Frequency percent \\
\hline Male & 185 & $\% 46 / 2$ \\
\hline Female & 215 & $\% 53 / 8$ \\
\hline Sum & 400 & $\% 100$ \\
\hline
\end{tabular}

As observed in table 2, it can observe that $53.8 \%$ and $46.2 \%$ of participants develop from females and males, respectively.

Table 3. Frequency distribution of education status of participants

\begin{tabular}{|l|c|c|}
\hline Education status & Frequency & Frequency percent \\
\hline Bachelor degree & 262 & $\% 65 / 5$ \\
\hline Master degree & 128 & $\% 32$ \\
\hline PhD & 10 & $\% 2 / 5$ \\
\hline Sum & 400 & $\% 100$ \\
\hline
\end{tabular}

Table 3 indicates frequency distribution of the research participants based on education status. As observed, $65.5 \%$, $32 \%$ and $2.5 \%$ of the research participants have bachelor degree, master degree and $\mathrm{PhD}$, respectively.

\subsubsection{Descriptive statistics relating to Defense Style Questionnaire (DSQ)}

Descriptive statistics relating to the Defense Style Questionnaire (DSQ) are proposed, represented with styles, mechanisms and questions.

Table 4. Descriptive statistics of Defense Style Questionnaire (DSQ)

\begin{tabular}{|l|c|c|c|c|c|c|}
\hline Scale & Mean & Average standard error & Standard deviation & Dispersion coefficient & Minimum & Maximum \\
\hline Defense Styles & $197 / 98$ & $1 / 52$ & $30 / 43$ & $\% 15 / 37$ & 116 & 288 \\
\hline
\end{tabular}

As observed in table 5, total mean of defense styles questionnaire equals to 197.98 .

Table 5. descriptive statistics pertaining to defense styles

\begin{tabular}{|l|c|c|c|c|c|c|}
\hline Styles & Mean & Average standard error & Standard deviation & Dispersion coefficient & Minimum & Maximum \\
\hline Immature & $110 / 60$ & $1 / 09$ & $21 / 80$ & $\% 19 / 71$ & 61 & 163 \\
\hline mature & $44 / 48$ & $0 / 44$ & $8 / 98$ & $\% 20 / 18$ & 18 & 72 \\
\hline Neuroticism & $42 / 89$ & $0 / 48$ & $9 / 64$ & $\% 22 / 47$ & 21 & 88 \\
\hline
\end{tabular}

Table 6 represents descriptive statistics relating to the style of defense. Mature style regarding the number of questions in each style has highest mean (48/44). Neurotic style has the highest coefficient of dispersion (47/22\%).

Table 6. Descriptive statistics of defense styles regarding each mechanism

\begin{tabular}{|l|c|c|c|c|c|c|}
\hline Mechanisms & Mean & Average standard error & Standard deviation & Dispersion coefficient & Minimum & Maximum \\
\hline Rationalization & $12 / 86$ & $0 / 17$ & $3 / 42$ & $\% 26 / 59$ & 2 & 18 \\
\hline Projection & $8 / 84$ & $0 / 17$ & $3 / 41$ & $\% 38 / 57$ & 2 & 18 \\
\hline
\end{tabular}




\begin{tabular}{|l|c|c|c|c|c|c|}
\hline & & & & & & \\
\hline denial & $8 / 31$ & $0 / 18$ & $3 / 62$ & $\% 43 / 56$ & 2 & 18 \\
\hline omnipotence & $10 / 33$ & $0 / 24$ & $4 / 85$ & $\% 46 / 95$ & 2 & 18 \\
\hline Idealization & $9 / 29$ & $0 / 18$ & $3 / 76$ & $\% 40 / 47$ & 2 & 18 \\
\hline transition to action & $8 / 98$ & $0 / 20$ & $4 / 04$ & $\% 44 / 98$ & 2 & 18 \\
\hline Somatization & $10 / 81$ & $0 / 21$ & $4 / 22$ & $\% 39 / 03$ & 2 & 18 \\
\hline autistic fantasy & $9 / 05$ & $0 / 24$ & $4 / 80$ & $\% 53 / 03$ & 2 & 18 \\
\hline layering & $8 / 11$ & $0 / 21$ & $4 / 24$ & $\% 52 / 28$ & 2 & 18 \\
\hline Passive aggression & $8 / 44$ & $0 / 20$ & $4 / 12$ & $\% 48 / 81$ & 2 & 18 \\
\hline Displacement & $7 / 39$ & $0 / 17$ & $3 / 56$ & $\% 48 / 17$ & 2 & 18 \\
\hline Isolation & $8 / 16$ & $0 / 21$ & $4 / 25$ & $\% 52 / 08$ & 2 & 18 \\
\hline Suppression & $10 / 20$ & $0 / 18$ & $3 / 72$ & $\% 36 / 47$ & 2 & 18 \\
\hline Sublimation & $9 / 73$ & $0 / 19$ & $3 / 91$ & $\% 40 / 18$ & 2 & 18 \\
\hline humor & $10 / 76$ & $0 / 19$ & $3 / 99$ & $\% 37 / 08$ & 2 & 18 \\
\hline anticipation & $13 / 77$ & $0 / 16$ & $3 / 26$ & $\% 23 / 67$ & 2 & 18 \\
\hline false friend & $12 / 25$ & $0 / 17$ & $3 / 44$ & $\% 28 / 08$ & 2 & 18 \\
\hline reaction formation & $8 / 72$ & $0 / 19$ & $3 / 84$ & $\% 44 / 03$ & 2 & 18 \\
\hline intellectualize & $10 / 91$ & $0 / 21$ & $4 / 25$ & $\% 38 / 95$ & 2 & 18 \\
\hline Cancellation & 11 & $0 / 21$ & $4 / 37$ & $\% 39 / 72$ & 2 & 18 \\
\hline
\end{tabular}

In table 6, descriptive statistics of the Defense Style Questionnaire (DSQ) concerning each mechanism have been proposed. As observed in table, anticipation mechanism has the highest mean (13.77) and displacement mechanism has the lowest mean (7.39). Further, mechanisms of rationalization, omnipotence, somatization, suppression, humor, anticipation, false friendship and cancellation have mean greater than 10. In this regards, mechanisms of rationalization, omnipotence and somatization are included of immature defense style, mechanisms of suppression, humor and anticipation are included of mature defense style and mechanisms of false friend, rationalization and cancellation are included of neurotic defense style. With regard to the dispersion coefficient column, it is specified that autistic fantasy has the highest dispersion coefficient (53.03\%). Indeed, dispersion of scores of participants is high in this mechanism. Further, anticipation mechanism has the least dispersion coefficient (23.67\%), indicating closeness of scores in this mechanism.

\subsubsection{Determination of reliability of Defense Style Questionnaire (DSQ)}

Two retest and Cronbach's Alpha methods were used to estimate reliability coefficient of defense styles questionnaire. Retest was used to evaluate reliability of Defense Style Questionnaire (DSQ). Defense Style Questionnaire (DSQ) was performed two times by 50 participants during 4 weeks. The correlation coefficient was obtained equal to 0.82 between two times performing test, indicating high reliability of Defense Style Questionnaire (DSQ). Further, test-retest correlation for mature, immature and neurotic factors was obtained equal to $0.78,0.65$ and 0.62 , respectively. With regard to scoring Defense Style Questionnaire (DSQ) ranging from 1 to 9 in Likert scales, Cronbach's Alpha has been used to determine internal consistency. Using this method, reliability of questionnaire has been obtained equal to 0.72 , which is an acceptable reliability.

Validity of Defense Style Questionnaire (DSQ)

Table 7. Size of KMO and result of Bartlett's test of sphericity

\begin{tabular}{|c|c|c|c|}
\hline Bartlett's test of sphericity & Freedom degree & Chi-square value & value of KMO \\
\hline $0 / 000$ & 780 & $2704 / 85$ & $0 / 66$ \\
\hline
\end{tabular}

As observed in table 7 , value of Kaiser - Meyer - Olkin (KMO) equals to 0.66 , thus adequacy of sampling is assumed suitable(this value must be greater than 0.5 ). 
Table 8. Squares and rotated factor loadings of three factors with Eigenvalue greater than 1

\begin{tabular}{|c|c|c|c|}
\hline No & \multicolumn{3}{|c|}{ Eigenvalue } \\
\hline & Eigenvalue & Variance percent & Density percent \\
\hline 1 & $3 / 78$ & $9 / 45$ & $9 / 45$ \\
\hline 2 & $3 / 10$ & $7 / 75$ & $17 / 20$ \\
\hline 3 & $2 / 20$ & $5 / 49$ & $22 / 70$ \\
\hline
\end{tabular}

As observed in table $8,9.45 \%, 7.75 \%$ and $5.49 \%$ of total variance relate to the first, second and third factor, respectively. Naming factors

In table 9, mean, standard deviation, average standard error, mean, median, dispersion coefficient, skewness, standard skewness error, elongation, standard elongation error, minimum and maximum factors have been indicated.

Table 9. Statistical indices of the factors included in Defense Style Questionnaire (DSQ)

\begin{tabular}{|l|c|c|c|}
\hline Statistical indices & Factor 1 Immature & Factor 2 Neurotic & Factor 3 Mature \\
\hline mean & $110 / 60$ & $42 / 89$ & $44 / 48$ \\
\hline average standard error & $1 / 09$ & $0 / 48$ & $0 / 44$ \\
\hline mean & 108 & 43 & 45 \\
\hline median & 104 & 48 & 40 \\
\hline standard deviation & $21 / 80$ & $9 / 64$ & $8 / 98$ \\
\hline dispersion coefficient & $\% 19 / 71$ & $\% 22 / 47$ & $\% 20 / 18$ \\
\hline skewness & $0 / 15$ & $0 / 31$ & $-0 / 11$ \\
\hline standard skewness error & $0 / 12$ & $0 / 12$ & $0 / 12$ \\
\hline elongation & $-0 / 43$ & $0 / 43$ & $0 / 31$ \\
\hline standard elongation error & $0 / 24$ & $0 / 24$ & $0 / 24$ \\
\hline minimum & 61 & 21 & 18 \\
\hline maximum & 163 & 88 & 72 \\
\hline
\end{tabular}

As shown in table 9, the highest dispersion coefficient relates to neurotic factor, indicating that scores of the individuals in this factor compared to other factors enjoy greater dispersion, i.e. scores of individuals are not congruent in this factor. The lowest dispersion coefficient relates to factor 1 (immature style), indicating scores of individuals in this factor compared to other factors enjoy less dispersion, i.e. scores of individuals in this factor are congruent. Further, with regard to partial differences between mean and median, it can say that distribution of each of factors above is symmetric. This statement is confirmed with an emphasis on skewness coefficient which is less than 1 ; in addition, it can say that the distribution above has been normal with an emphasis on elongation coefficient which is less than 1 .

The relationship between defensive styles and coping strategies under stressful conditions

Pearson correlation coefficient was used to examine correlation between Defense Style Questionnaire (DSQ) and its factors related to coping strategies with stressful conditions. The questionnaire of coping with stressful conditions was prepared by Endler \& Parker (1990) so as to evaluate how the individuals cope with their problems. This test consists of 48 terms and three coping styles including Task-oriented coping, Emotion-oriented coping and Avoidance-oriented coping. Each style consists of 16 terms. Results from correlation coefficients have been represented in table 10.

Table 10. Correlation between defensive styles questionnaire and coping with stress strategies

\begin{tabular}{|l|c|c|c|c|c|c|c|c|}
\hline Scales & \multicolumn{2}{|c|}{ Defense Style Questionnaire (DSQ) } & \multicolumn{2}{l|}{ Immature style } & \multicolumn{2}{|c|}{ Mature style } & \multicolumn{2}{c|}{ Neurotic style } \\
\hline \multirow{2}{*}{$\begin{array}{l}\text { The questionnaire of coping strategies } \\
\text { with stress }\end{array}$} & $\mathrm{r}$ & $\mathrm{sig}$ & $\mathrm{r}$ & $\mathrm{sig}$ & $\mathrm{r}$ & $\mathrm{sig}$ & $\mathrm{r}$ & $\mathrm{sig}$ \\
\cline { 2 - 7 } & $0 / 34$ & $0 / 000$ & $0 / 24$ & $0 / 016$ & $0 / 20$ & $0 / 043$ & $0 / 37$ & $0 / 000$ \\
\hline Task-oriented coping & $0 / 19$ & $0 / 051$ & $0 / 014$ & $0 / 891$ & $0 / 35$ & $0 / 000$ & $0 / 27$ & $0 / 006$ \\
\hline Emotion-oriented coping & $0 / 17$ & $0 / 083$ & $0 / 21$ & $0 / 029$ & $-0 / 19$ & $0 / 052$ & $0 / 22$ & $0 / 023$ \\
\hline Avoidance-oriented coping & $0 / 25$ & $0 / 012$ & $0 / 16$ & $0 / 092$ & $0 / 26$ & $0 / 008$ & $0 / 19$ & $0 / 058$ \\
\hline
\end{tabular}

R: Pearson correlation coefficient

Sig: significance level

As shown in table 10 , there is a positive significant correlation( $r=0.34)$ between total score of Defense Style 
Questionnaire (DSQ) and total score of coping strategies to deal with stress, i.e. the more scores of Defense Style Questionnaire (DSQ), scores of coping strategies with stress increase and vice versa. Therefore, there is a positive significant relationship between Defense Style Questionnaire (DSQ) and coping strategies with stress. There is a positive significant relationship( $r=0.25)$ between Defense Style Questionnaire (DSQ) and Avoidance-oriented coping. Among defensive styles, neurotic style has the highest correlation (0.37) with coping strategies with stress, i.e. there is a positive significant relationship between neurotic style and coping strategies with stress. Further, there is a positive significant relationship( $r=0.35)$ between mature style and task-oriented coping. Indeed, there is a positive significant relationship between mature style and Task-oriented coping.

Comparison of Defense Style Questionnaire (DSQ) in terms of gender

To compare defense styles and its mechanisms between men and women, t-test has been used.

Table 11. Comparison of defense style questionnaire between men and women

\begin{tabular}{|l|c|c|c|c|}
\hline Gender & Mean & Freedom degre & t-value & sig \\
\cline { 1 - 2 } Women & $199 / 34$ & 398 & $0 / 96$ & $0 / 33$ \\
\hline Men & $196 / 39$ & & & \\
\hline
\end{tabular}

As observed in table 11, there is no significant difference on total mean of defense style questionnaire between men and women.

Table 12. Comparison of defense styles between men and women

\begin{tabular}{|l|c|c|c|c|c|}
\hline Style & Gender & Mean & Freedom degree & -value t & sig \\
\hline \multirow{2}{*}{ Immature } & Female & $112 / 03$ & 398 & $1 / 41$ & $0 / 15$ \\
\cline { 2 - 3 } & Male & $108 / 94$ & & & \\
\hline \multirow{2}{*}{ Mature } & Female & $44 / 53$ & 398 & $0 / 12$ & $0 / 90$ \\
\cline { 2 - 3 } & Male & $44 / 42$ & & & \\
\hline \multirow{2}{*}{ Neurotic } & Female & $42 / 78$ & 398 & $-0 / 24$ & $0 / 80$ \\
\cline { 2 - 3 } & Male & $43 / 02$ & & & \\
\hline
\end{tabular}

Comparison of mean of defense styles between men and women has been indicated in table 12. As observed in table, there is no significant difference on defense styles between men and women.

Table 13. Comparison of defensive mechanisms between men and women

\begin{tabular}{|c|c|c|c|c|c|}
\hline Defensive mechanisms & Gender & Mean & Freedom degree & -value t & sig \\
\hline \multirow[t]{2}{*}{ Rationalization } & Female & $12 / 73$ & \multirow[t]{2}{*}{398} & \multirow[t]{2}{*}{$-0 / 78$} & \multirow[t]{2}{*}{$0 / 43$} \\
\hline & Male & $13 / 00$ & & & \\
\hline \multirow[t]{2}{*}{ Projection } & Female & $8 / 85$ & \multirow[t]{2}{*}{398} & \multirow[t]{2}{*}{ 0/07 } & \multirow[t]{2}{*}{$0 / 94$} \\
\hline & Male & $8 / 82$ & & & \\
\hline \multirow[t]{2}{*}{ denial } & Female & $8 / 22$ & \multirow[t]{2}{*}{398} & \multirow[t]{2}{*}{$-0 / 50$} & \multirow[t]{2}{*}{$0 / 61$} \\
\hline & Male & $8 / 41$ & & & \\
\hline \multirow[t]{2}{*}{ omnipotence } & Female & $10 / 53$ & \multirow[t]{2}{*}{398} & \multirow[t]{2}{*}{$0 / 91$} & \multirow[t]{2}{*}{$0 / 36$} \\
\hline & Male & $10 / 09$ & & & \\
\hline \multirow[t]{2}{*}{ Idealization } & Female & $9 / 95$ & \multirow[t]{2}{*}{398} & \multirow[t]{2}{*}{$3 / 86$} & \multirow[t]{2}{*}{$0 / 000 *$} \\
\hline & Male & $8 / 51$ & & & \\
\hline \multirow[t]{2}{*}{ transition to action } & Female & 9/42 & \multirow[t]{2}{*}{398} & \multirow[t]{2}{*}{$2 / 36$} & \multirow[t]{2}{*}{ 0/01* } \\
\hline & Male & $8 / 47$ & & & \\
\hline \multirow[t]{2}{*}{ Somatization } & Female & $11 / 45$ & \multirow[t]{2}{*}{398} & \multirow[t]{2}{*}{$3 / 32$} & \multirow[t]{2}{*}{ 0/001* } \\
\hline & Male & $10 / 06$ & & & \\
\hline \multirow[t]{2}{*}{ autistic fantasy } & Female & $8 / 98$ & \multirow[t]{2}{*}{398} & \multirow[t]{2}{*}{$-0 / 34$} & \multirow[t]{2}{*}{$0 / 73$} \\
\hline & Male & 9/14 & & & \\
\hline \multirow[t]{2}{*}{ layering } & Female & $8 / 28$ & \multirow[t]{2}{*}{398} & \multirow[t]{2}{*}{$0 / 90$} & \multirow[t]{2}{*}{$0 / 36$} \\
\hline & Male & $7 / 90$ & & & \\
\hline Passive aggression & Female & $8 / 34$ & 398 & $-0 / 50$ & $0 / 61$ \\
\hline
\end{tabular}




\begin{tabular}{|c|c|c|c|c|c|}
\hline & Male & $8 / 55$ & & & \\
\hline \multirow[t]{2}{*}{ Displacement } & Female & $7 / 57$ & \multirow[t]{2}{*}{398} & \multirow[t]{2}{*}{$1 / 05$} & \multirow[t]{2}{*}{$0 / 29$} \\
\hline & Male & $7 / 19$ & & & \\
\hline \multirow[t]{2}{*}{ Isolation } & Female & $7 / 66$ & \multirow[t]{2}{*}{398} & \multirow[t]{2}{*}{$-2 / 58$} & \multirow[t]{2}{*}{$0 / 01 *$} \\
\hline & Male & $8 / 75$ & & & \\
\hline \multirow[t]{2}{*}{ Suppression } & Female & $10 / 32$ & \multirow[t]{2}{*}{398} & \multirow[t]{2}{*}{$0 / 68$} & \multirow[t]{2}{*}{$0 / 49$} \\
\hline & Male & $10 / 07$ & & & \\
\hline \multirow[t]{2}{*}{ Sublimation } & Female & $9 / 91$ & \multirow[t]{2}{*}{398} & \multirow[t]{2}{*}{$1 / 01$} & \multirow[t]{2}{*}{$0 / 31$} \\
\hline & Male & $9 / 51$ & & & \\
\hline humor & $\begin{array}{c}\text { Female } \\
\text { Male }\end{array}$ & $\begin{array}{l}10 / 58 \\
10 / 97\end{array}$ & 398 & $-0 / 97$ & $0 / 32$ \\
\hline \multirow[t]{2}{*}{ anticipation } & Female & $13 / 70$ & \multirow[t]{2}{*}{398} & \multirow[t]{2}{*}{$-0 / 46$} & \multirow[t]{2}{*}{$0 / 64$} \\
\hline & Male & $13 / 85$ & & & \\
\hline \multirow[t]{2}{*}{ false friend } & Female & $12 / 13$ & \multirow[t]{2}{*}{398} & \multirow[t]{2}{*}{$-0 / 73$} & \multirow[t]{2}{*}{$0 / 46$} \\
\hline & Male & $12 / 38$ & & & \\
\hline \multirow[t]{2}{*}{ reaction formation } & Female & $8 / 78$ & \multirow[t]{2}{*}{398} & \multirow[t]{2}{*}{$0 / 32$} & \multirow[t]{2}{*}{$0 / 74$} \\
\hline & Male & $8 / 65$ & & & \\
\hline \multirow[t]{2}{*}{ intellectualize } & Female & $11 / 20$ & \multirow[t]{2}{*}{398} & \multirow[t]{2}{*}{$1 / 49$} & \multirow[t]{2}{*}{$0 / 13$} \\
\hline & Male & $10 / 56$ & & & \\
\hline \multirow[t]{2}{*}{ Cancellation } & Female & $10 / 66$ & \multirow[t]{2}{*}{398} & \multirow[t]{2}{*}{$-1 / 71$} & \multirow[t]{2}{*}{$0 / 08$} \\
\hline & Male & $11 / 41$ & & & \\
\hline
\end{tabular}

*significant difference

Comparison of mean of defensive mechanisms between men and women has been represented in table 20. As observed, there is a significant difference on mean of mechanisms of transition to action, idealization, somatization and isolation between men and women. With overview of means, it is specified that mean of mechanisms of transition to action, idealization, somatization is greater in women than men. Further, mean of isolation mechanism is greater in men than women. There is no significant difference on other defensive mechanisms between men and women. Mechanisms of Rationalization, omnipotence, suppression, humor, anticipation, false friend, intellectualize and cancellation has mean greater than 10 .

Comparison of Defense Style Questionnaire (DSQ) in terms of education status

ANOVA has been used to compare Defense Style Questionnaire (DSQ) in terms of education status.

Table 14. Comparison of Defense Style Questionnaire (DSQ) in terms of education status

\begin{tabular}{|c|c|c|c|c|}
\hline Education status & Mean & Freedom degree & -value $t$ & sig \\
\hline Bachelor degree & $200 / 52$ & \multirow[t]{3}{*}{2} & \multirow{3}{*}{$4 / 2$} & \multirow{3}{*}{$0 / 016^{*}$} \\
\hline Master degree & $194 / 39$ & & & \\
\hline $\mathrm{PhD}$ & $177 / 2$ & & & \\
\hline
\end{tabular}

*significant difference

As observed in table 14, there is a significant difference on mean of Defense Style Questionnaire (DSQ) in terms of education status. In following, Tukey post-hoc test is used to find the differences.

Table 15. Tukey post-hoc test to compare education status

\begin{tabular}{|c|c|c|}
\hline Education status & Difference of mean & Sig \\
\hline Bachelor degree- Master degree & $6 / 12$ & $0 / 14$ \\
\hline Bachelor degree- $\mathrm{PhD}$ & $23 / 32$ & $0 / 045 *$ \\
\hline Master degree - PhD & $17 / 19$ & $0 / 19$ \\
\hline
\end{tabular}

*significant difference

As observed in table 15, there is a significant difference on total mean of Defense Style Questionnaire (DSQ) in terms of education status between bachelor degree and $\mathrm{PhD}(\mathrm{p}=0.045)$. With overview of means of two education statuses, it is specified that mean of bachelor's degree students is greater than mean of PhD students. 
Table 16. Comparison of Defense Style Questionnaire (DSQ) in terms of education status

\begin{tabular}{|c|c|c|c|c|c|}
\hline Style & Education status & Mean & Freedom degree & -value t & sig \\
\hline \multirow{3}{*}{ Immature } & Bachelor degree & $113 / 25$ & \multirow[t]{3}{*}{2} & \multirow[t]{3}{*}{$7 / 44$} & \multirow[t]{3}{*}{ 0/0 01* } \\
\hline & Master degree & $106 / 50$ & & & \\
\hline & $\mathrm{PhD}$ & $93 / 7$ & & & \\
\hline \multirow{3}{*}{ Mature } & Bachelor degree & $44 / 42$ & \multirow[t]{3}{*}{2} & \multirow[t]{3}{*}{$0 / 97$} & \multirow[t]{3}{*}{$0 / 37$} \\
\hline & Master degree & $44 / 88$ & & & \\
\hline & $\mathrm{PhD}$ & $40 / 80$ & & & \\
\hline \multirow{3}{*}{ Neurotic } & Bachelor degree & $42 / 84$ & \multirow[t]{3}{*}{2} & \multirow[t]{3}{*}{$0 / 015$} & \multirow[t]{3}{*}{$0 / 98$} \\
\hline & Master degree & $43 / 01$ & & & \\
\hline & PhD & $42 / 70$ & & & \\
\hline
\end{tabular}

*significant difference

Comparison of Defense Style Questionnaire (DSQ) in terms of education status has been represented in table 16. As observed in table, there is a significant difference on mean of immature defense style between different education statuses. There is not a significant difference on two mature and neurotic styles between two education statuses. There is just a significant difference on immature style, thus in following the differences will be clarified using Tukey post-hoc test.

Table 17. Tukey post-hoc test to compare education statuses in immature style

\begin{tabular}{|l|c|c|}
\hline Education status & Difference of mean & sig \\
\cline { 2 - 3 } & $6 / 75$ & $0 / 01^{*}$ \\
\cline { 2 - 3 } & $0 / 014^{*}$ \\
\cline { 2 - 3 } & $19 / 55$ & $0 / 16$ \\
\hline
\end{tabular}

*significant difference

As observed in table 17, there is a significant difference on mean of immature defense style between bachelor degree and master degree and there is a significant difference on mean of immature defense style between bachelor degree and $\mathrm{PhD}$. With overview of means, it is specified that mean of immature defense style is greater in bachelore degree than master degree and PhD.

Table 18. Comparison of Defense Style Questionnaire (DSQ) in terms of education status

\begin{tabular}{|c|c|c|c|c|c|}
\hline Defensive mechanisms & education status & Mean & Freedom degree & -value $\mathrm{t}$ & sig \\
\hline \multirow{3}{*}{ Rationalization } & Bachelor degree & $12 / 72$ & \multirow[t]{3}{*}{2} & \multirow[t]{3}{*}{$2 / 29$} & \multirow[t]{3}{*}{$0 / 10$} \\
\hline & Master degree & $13 / 26$ & & & \\
\hline & $\mathrm{PhD}$ & $11 / 2$ & & & \\
\hline \multirow{3}{*}{ Projection } & Bachelor degree & $8 / 80$ & \multirow[t]{3}{*}{2} & \multirow[t]{3}{*}{$0 / 04$} & \multirow[t]{3}{*}{$0 / 95$} \\
\hline & Master degree & $8 / 91$ & & & \\
\hline & $\mathrm{PhD}$ & $8 / 9$ & & & \\
\hline \multirow{3}{*}{ denial } & Bachelor degree & $8 / 47$ & \multirow[t]{3}{*}{2} & \multirow[t]{3}{*}{$1 / 47$} & \multirow[t]{3}{*}{$0 / 22$} \\
\hline & Master degree & $8 / 10$ & & & \\
\hline & $\mathrm{PhD}$ & $6 / 7$ & & & \\
\hline \multirow{3}{*}{ omnipotence } & Bachelor degree & $10 / 52$ & \multirow[t]{3}{*}{398} & \multirow[t]{3}{*}{$0 / 67$} & \multirow[t]{3}{*}{$0 / 51$} \\
\hline & Master degree & $9 / 99$ & & & \\
\hline & $\mathrm{PhD}$ & $9 / 5$ & & & \\
\hline \multirow{3}{*}{ Idealization } & Bachelor degree & 9/66 & \multirow[t]{3}{*}{2} & \multirow[t]{3}{*}{$6 / 65$} & \multirow[t]{3}{*}{ 0/001* } \\
\hline & Master degree & $8 / 78$ & & & \\
\hline & $\mathrm{PhD}$ & $5 / 9$ & & & \\
\hline \multirow{3}{*}{ transition to action } & Bachelor degree & $9 / 15$ & \multirow[t]{3}{*}{2} & \multirow[t]{3}{*}{$0 / 73$} & \multirow[t]{3}{*}{$0 / 47$} \\
\hline & Master degree & $8 / 62$ & & & \\
\hline & PhD & $9 / 1$ & & & \\
\hline \multirow{3}{*}{ Somatization } & Bachelor degree & $11 / 20$ & \multirow[t]{3}{*}{2} & \multirow[t]{3}{*}{$3 / 31$} & \multirow[t]{3}{*}{ 0/037* } \\
\hline & Master degree & $10 / 10$ & & & \\
\hline & $\mathrm{PhD}$ & $9 / 7$ & & & \\
\hline
\end{tabular}




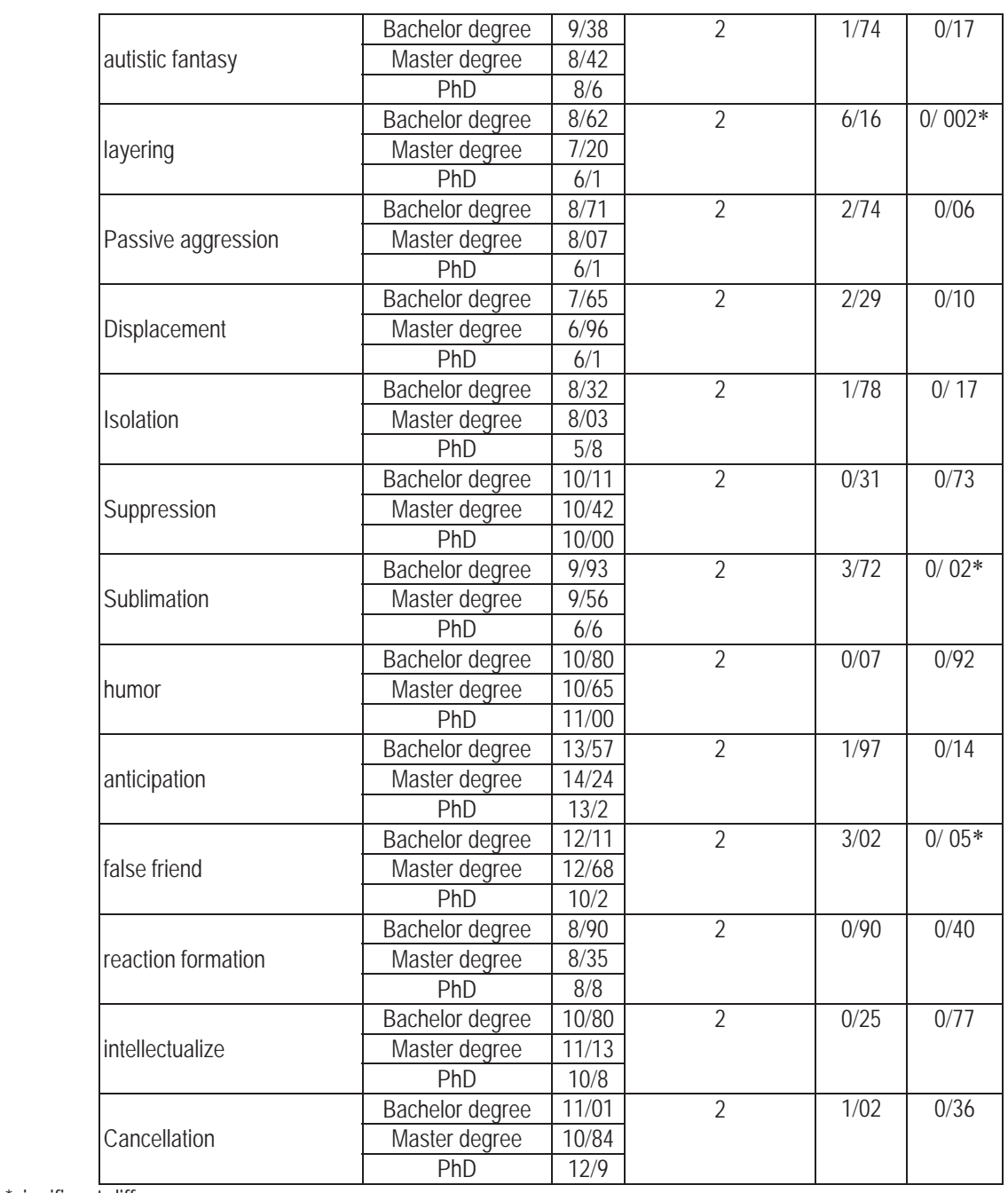

*significant difference

Mean of defensive mechanisms regarding education status has been compared in table 18. As observe in table, there is a significant difference on mean of mechanisms of idealization, Somatization, layering, sublimation and false friend between education statuses. With overview of means, it is specified that mean of education status of bachelor degree and master degree students in mechanisms of idealization, Somatization, layering, sublimation and false friend is greater than mean of education status of PhD students in these mechanisms.

\section{Discussion and Conclusion}

After analyzing data and achieving findings of research using statistical methods, results from questions are discussed to give response to the questions raised in the research. To give response to the first question of research "whether defense style questionnaire enjoys favorable validity and reliability?", internal consistency method and Cronbach's alpha have been used to examine validity of defense style questionnaire. With regard to the results, internal consistency was obtained equal to 0.720 for the questionnaire consisting of 40 questions. Correlation coefficient of each question with total score indicates that such questionnaire enjoys a proper internal consistency, ensured on the results from factor analysis. This result confirms the research by Heidari nasab et al.(2007). In a research by Heidari Nasab et al.(2007), this 
questionnaire was examined and normalized that the findings related to the validity specified that Iranian Iranian version of questionnaire likewise original version enjoys favorable validity. Validity coefficient of this questionnaire using Cronbach's alpha was obtained equal to 0.71 and 0.78 for school students and university students and the Split-half correlation coefficient was obtained equal to 0.54 . In France, Brazil and Portugal, it was specified that France, Brazil and Portugal version has a similar psychometric composition with the original scale; this questionnaire has been considered as a suitable instrument, enjoyed a favorable validity (Bonsack, C., Despland, J., Spagnoli, J. 1998; Blaya, C., Kipper, L., Heldt, M., Isolan, L., ceitlin, L. Bond, M. Manfro, G., quoted from Ashtiani, 2011). To give response to this research question "whether defense style questionnaire enjoys a favorable validity" and examine validity of construct and examine what factors have saturated scale of defense style questionnaire, analysis of major components was used. Factor analysis has four major stages: 1-preparation of correlation matrix from variables and estimation of their commonality, 2extraction of factors, 3-selection and rotation of factors, 4-intepretation of results. Value of Kaiser- Meyer- Olkin (KMO) equals to 0.66 , thus adequacy of sampling is considered suitable. To examine whether correlation matrix of data is not zero in the population, Bartlett's Test of sphericity was used. This test has been targeted in rejecting null hypothesis based on correctness of identity matrix, that is, the matrix with diagonal elements equal to 1 and non-diagonal elements equal to 0 . Bartlett test of this hypothesis tests the matrix of observed correlations which belong to the population with uncorrelated variables. The variables must be correlated in order that the factor model has meaning, otherwise there is no reason to elaborate factor model. In the present research, statistical value of Bartlett test equals to 2704.85 at $\mathrm{P}=0.000$. Therefore, it can say that there is a correlation between variables in the population. The scores of the data from test indicated that questions to different degrees are correlated with each other. The least commonality $(0.46)$ relates to question 6 (people tend to mistreat me) and the utmost commonality (0.75) relates to question 14 (I enjoy my dreams more than my real life), i.e. there is an overlap and interact between them. These scroes must be analyzed to prepare a fundamental structure so as to detect the characteristics under study with fewer dimensions. Principal structure of component analysis and factor analysis has been developed for this purpose. In this research, to know what factors have saturated defense style questionnaire, analysis of major components has been used. With regard to this method, value (1) is set in each of diagonal boxes of correlation matrix. This method seeks a structure which determines variance of all the variables under study (Thorndike, trans-Homan, 1996). To determine diagnosis responses of the factor or factors which develop the infrastructure of defense style questionnaire and to determine simple structure of questionnaire, principal components analysis (with varimax rotation) has been used. Eigenvalue of 15 factors based on data is greater than 1.15 factors determine $61.17 \%$ of variance of all the variables. 3 factors among 15 factors determine $22.70 \%$ of total variance.

- factor 1 indicates immature defense style.

- factor 2 indicates mature defense style.

- factor 3 indicates neurotic defense style.

Factor 1 indicates immature defense style. In this style, defensive mechanisms include Rationalization, Projection, denial, omnipotence, Idealization, transition to action, Somatization, autistic fantasy, layering, Passive aggression, Displacement, Isolation. Literature review indicates that such defense style refers to unconsciousness strategies that assist the individuals to keep their thoughts, feelings, memoirs and frustrating fears far from consciousness (Villant, G. 1977, 2000). This defensive style will be considered among denied defense mechanisms in Diagnostic and Statistical Manual of Mental Disorders, Fifth Edition (DSM-5)(APA, 2000). Factor 2 indicates mature defense style which includes mechanisms of Suppression, Sublimation, humor, anticipation. Literature review indicates that defenses regulate negative impacts which are acquired through the balance between unacceptable impulses and prosocial desires. This balance increases the probability for satisfaction. Further, when balance is acquired, Conflict impulses, desires, demands, personal forces and related emotion are kept in vigilance (Villant, 1994). Such defenses refer to adaptive defenses against healthy responses to stressful situations. According to point of view of Villant, this defensive style is considered at mature defense levels. Factor 3 indicates neurotic defensive style, which includes false friend, reaction formation, intellectualize, Cancellation. At neurotic defense level, defenses regulate negative impacts through holding unacceptable wishes out of consciousness. At neurotic defense level, defenses regulate negative impacts by holding unacceptable wishes out of consciousness. This defense style is considered at defense levels. Further, Andrews, G., Singh, M. \& Bond, M.(1993) have referred to neurotic defense mechanisms. Hayashi et al.(2004) performed DSQ questionnaire in Japan and acquired four factors based on factor analysis based on Varimax. The first factor has included of mature and immature defenses, included Anderos's immature second factors and found as the only mechanism of reaction formation which has been in Andrews's checklist as a neurotic defense and the third factor has been combined of neurotic and immature defenses. In response to the fourth research question "whether a relationship exists between defensive mechanisms and coping strategies", Pearson correlation coefficient was used to examine correlation in defense style 
questionnaire and its related factors with Coping inventory for stressful situation. Coping Inventory for stressful situation (1990)was prepared by Endler \& Parker to evaluate how the individuals encounter with their problems. Correlation of criterion variable (coping styles) with defensive styles equals to 0.34 and square correlation value equals to 0.1156 .

With regard to the results from variance analysis test which are significant at level under 0.001 , it can conclude that there is a positive significant relationship between defense style questionnaire and Coping inventory for stressful situation. There is a positive significant relationship $(r=0.25)$ between defense style questionnaire and avoidant-based coping. Among defense styles, avoidant-based defense style has a positive significant relationship $(r=0.37)$ with Coping inventory for stressful situation. Further, there is a positive significant relationship $(r=0.35)$ between mature style and problem-based strategy. In the research by Liaghat et al.(2014) entitled "the relationship between coping strategies and defensive mechanisms and marital adjustment", a positive relationship was observed between coping strategies and defensive mechanisms. Further, this research indicated that there is a positive significant relationship between mature defensive mechanism and problem-based coping strategy, confirmed the obtained result. In response to the fifth question "whether a significant difference exists between defensive mechanisms between men and women?", t-test was used to compare defense styles and mechanisms between men and women, indicated that there is not a significant difference on mean of defense style questionnaire between men and women. However mean of scores of women in use of immature style has been higher than men, the difference has not been significant. There is not a significant difference on mechanisms of idealization, transition to practice, Somatization and isolation. With overview of means, it is specified that mean of mechanisms of idealization, transition to practice and somatization in women is greater than men. Further, mean of isolation mechanism is greater among men than women. These findings confirm studies by Costa, P. \& MC care(1992), indicated that women have higher scores in neuroticism than men, indicating use of immature systems with difference in both genders.

\section{References}

Heidari Nasab, L. Mansour, M. Azad Falah, Sh. 2007, validity of defense style questionnaire among Iranian samples, scientific-research journal of Shahed university, fourthteenth year, no. 22.

Heidari Nasab, L. 2006, comparison of defensive mechanisms in clinical and non-clinical samples based on normalization and findings based on psychometry of Iranian questonaire of defense styles, $\mathrm{PhD}$ thesis of Tarbiat Modares University.

Heidari Nasab, L. Shaeiri, MR. 2011, factor analysis of defense style questionnaire in non-clinical Iranian samples, journal of novel psychological research, 2th year, issue 21, 2011.

Azizi, A, Mirzaei, A. Shams, J. 2010, overview of the relationship between distress tolerance and emotion regulation, research journal of Hakim, 2010, course 13, issue 1.

Mohammad Pour Yazdi, AR, Doktor pezeshk, B. Dr Fata, L, Dr Dojkam, M. 2009, a study on defense styles and state anxiety among students with anxiety disorder, research and scientific journal of mental health principles, 2009, 11th, issue 1, pp. 7-14.

Blaya, C: dornelles. M. Blaya. R. Kipper, L. Heldt. E Isolan. L Band, M. and man fro, G. Do defense mechanism very according to the psychiafrc disorder? Rev Bras psiquiatr (2006); 28 (3): 179- 183.

Bond, M. and perny, J. C. long- Tern changes in Defense styles With psychooly namic psychotherapy for Depressive. Anviety, and personality Diserders. America $n$ Journal of psychiotry 2004; 161. 1665-71

Costa, P. T; MC caree, RR (2005). Chongng minds, big five factors. National inst, futes of meath, 21 (5). 3030307.

Cremer, P. Defense Mechanisms in psychologe foday. Journal of American psychology 2000, 55 (6): 637646.

Lazaros R cognition and motivation in emotion. Am psycho 1991, 46: 352- 67

Lynch T.R. M. Zon G. A. Distress over. Tolerance and distress intalomnce A behavioral perspective. In Zvolensky M. J. I Bernstein A. : vujanovic A. A: editors New York: Quilford press. 